\title{
Is it possible to substitute the monofilament test for the Ipswich Touch Test in screening for peripheral diabetic neuropathy?
}

\author{
Luz Marina Alfonso Dutra ${ }^{1 *}$, Mirian Conceição Moura², Flaviene Alves do Prado' ${ }^{1}$ Giselle De Oliveira Lima', \\ Manuela Costa Melo ${ }^{3}$, Rubens Nelson Morato Fernandez ${ }^{1}$ and Maria Rita Carvalho Garbi Novaes ${ }^{4}$
}

\begin{abstract}
Background: This study aimed to assess the agreement and efficacy of the Ipswich Touch Test compared to the monofilament test in individuals with type 2 diabetes.

Materials and methods: A cross-sectional and analytical study was conducted. The inclusion criteria were patients with type II diabetes $(n=250)$ who did not present ulcers or amputation in either foot. The exclusion criteria were as follows: patients who presented sequelae of cerebrovascular disease or other neurological pathologies, as well as diagnoses of malignancy, alcohol abuse, liver cirrhosis, hepatitis B, AIDS, hypothyroidism, chronic kidney disease or lupus erythaematosus, as these clinical conditions could influence or bias the results (Won and Park in Endocrinol Metab 31:230-238, 2016). Sensitivity, specificity, predictive values, likelihood ratios, and Kappa index were calculated. Other factors assessed were glycated haemoglobin and body mass index.
\end{abstract}

Results: Most of the participants were female (71.2\%), and glycated haemoglobin ( $\mathrm{HbA} 1 \mathrm{c}$ ) was greater than $7 \%$ in $54.4 \%$ of the patients. The mean age was 59.43 years, and the mean time since diagnosis was 12.38 years. The Kappa index was $0.819(p<0.001)$, and the Ipswich Touch Test had a sensitivity of $83.33 \%$, a specificity of $97.66 \%$, a positive predictive value of $85.71 \%$, a negative predictive value of $97.21 \%$, a positive likelihood ratio of $30.19 \%$, and a negative likelihood ratio of $0.17 \%$. The level of significance was $5 \%$ in this study.

Conclusion: The Ipswich Touch Test resented good agreement and efficacy compared to the gold standard-the $10 \mathrm{~g}$ monofilament test.

Keywords: Adult health, Diabetic foot, Diabetes mellitus, Diabetes neuropathies, Secondary care

\section{Background}

Diabetic neuropathy is a complication of chronic diabetes and results from heterogeneous conditions that impair nerve conduction $[1,2]$. Distal symmetric polyneuropathy (DSP) is the most common complication of both types of diabetes [3] and accounts for peripheral nerve dysfunction in diabetic patients after the exclusion of other types of diabetes, such as traumatic or neoplastic

\footnotetext{
*Correspondence: marinayyu95@gmail.com

1 Department of Health, Brasilia, Federal District, Brazil

Full list of author information is available at the end of the article
}

conditions, and other systemic diseases [4]. Distal symmetric polyneuropathy (DSP) depends on the length of the neuron [3], and may account for $75 \%$ of diabetic neuropathies [5, 6]. DSP is an important cause of foot ulceration and Charcot arthropathy [7], leading to amputation and increases in economic costs [8].

Manifestations of DSP can vary from subclinical symptoms to painful ones, such as burning, tingling, itching or prickling [3]. The pain is insidious and increases in severity due to the impairment of the peripheral neurons. It can affect the quality of life and mobility of patients and

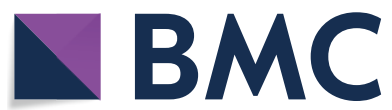

c The Author(s) 2020. This article is licensed under a Creative Commons Attribution 4.0 International License, which permits use, sharing, adaptation, distribution and reproduction in any medium or format, as long as you give appropriate credit to the original author(s) and the source, provide a link to the Creative Commons licence, and indicate if changes were made. The images or other third party material in this article are included in the article's Creative Commons licence, unless indicated otherwise in a credit line to the material. If material is not included in the article's Creative Commons licence and your intended use is not permitted by statutory regulation or exceeds the permitted use, you will need to obtain permission directly from the copyright holder. To view a copy of this licence, visit http://creativeco mmons.org/licenses/by/4.0/. The Creative Commons Public Domain Dedication waiver (http://creativecommons.org/publicdomain/ zero/1.0/) applies to the data made available in this article, unless otherwise stated in a credit line to the data. 
can lead to mood disorders and relationship problems in patients $[8,9]$.

The guidelines of the American Diabetes Association (ADA) and the Brazilian Diabetes Society (SBD) recommend that all people with diabetes should receive at least one foot assessment annually to identify risk factors for ulceration or amputation and that these foot assessments should begin immediately after diagnosis with type 2 diabetes and 5 years after diagnosis with type 1 diabetes [10, 11 .

The Ipswich Touch Test (IpTT) [12] is a simple way to conduct a screening test, principally in places with poor resources. Furthermore, the IpTT can be carried out by any trained health professional and simply involves lightly touching the tips of the first, third and fifth toes and the dorsum of the hallux with the index finger for 1-2 s. Further studies in different locations are necessary to gather more information about the IpTT and to validate this test [13].

Accordingly, this study aimed to evaluate the agreement and efficacy of the IpTT in relation to the monofilament test in individuals with type 2 diabetes, to contribute to the existing literature by providing evidence for a simpler screening technique, and to provide a test that can be undertaken at an early stage to avoid ulceration.

\section{Methods}

\section{Participants}

In total, 250 individuals who attended a diabetes outpatient centre were assessed. The inclusion criteria were as follows: individuals with type 2 diabetes who did not present ulcers or amputation in either foot. The exclusion criteria were as follows: patients who presented sequelae of cerebrovascular disease or other neurological pathologies, as well as diagnoses of malignancy, alcohol abuse, liver cirrhosis, hepatitis B, AIDS, hypothyroidism, chronic kidney disease or lupus erythaematosus, as these clinical conditions could influence or bias the results. [14].

\section{Study design and setting}

This is a cross-sectional and analytical study conducted at a centre specializing in diabetic patients located in the centre of Brasília. The centre also specializes in patients with foot pathologies. The data were collected between September 2017 and March 2018.

\section{Data collection}

The individuals were assessed in a quiet environment to avoid any noise that could have interfered with the results. The tests were conducted by physicians and nurses; a total of 6 professionals were trained to carry out the tests.

The gold standard test for the triage of the risk of ulceration is the $10 \mathrm{~g}$ monofilament test. It must be applied perpendicularly for a period of approximately $2 \mathrm{~s}$ in the base of the hallux in the 1st, 3rd, and 5th metatarsi heads. The patient must be asked to say "yes" when the area being tested is touched with a strength that is just enough to provoke the monofilament to curve for $2 \mathrm{~s}$. A simulation of the application and another concrete application in the same areas confirm that the patient has identified the site tested only when two answers are correct; any insensitive area indicates loss of plantar protective sensitivity. The test is not recommended on sites where there are scars, callosities, hyperkeratosis, since these may lead to errors in the results.

The monofilament test was complemented with a $125 \mathrm{~Hz}$ tuning fork placed on the dorsum of the hallux for a period of $2 \mathrm{~s}$ as a means of complementing the test $[11,15]$. The monofilament fibre was used to assess a maximum of 10 patients/day.

The IpTT was undertaken using the tip of the index finger for a period of approximately $2 \mathrm{~s}$ on the tips of the first, third and fifth toes.

When both tests presented 2 negative points, the results were considered to be negative. Individuals were asked to close their eyes when they received the tests and to respond with the word "yes" when they felt the touch. Tests were carried out by experienced professionals who had been trained and worked in the institution for a long time, in secondary health care. Each participant underwent the monofilament test at least twice, and whenever the test was inconclusive or its results unclear, another professional was asked to carry out an evaluation, to avoid bias in the results.

The values for glycated haemoglobin and Body mass index (BMI), taken from electronic medical records, were also taken into account.

To classify the severity of the symptoms, the researchers used the instrument for screening symptoms developed by the Federal District's State Department of Health and in conjunction with the Brazilian Diabetes Society, following the recommendations of the International Working Group on the Diabetic Foot (IWGDF) [16, 17]. The clinical symptoms were assessed in relation to pain, burning and tingling and were compared using a visual analogue scale from 0 to 10 , with 10 being the maximum pain reported.

These algorithms allow the results to be classified as follows: symptoms scoring from 0 to 2 points are normal; from 3 to 4 points are mild; from 5 to 6 points are moderate; and from 7 to 9 points are severe. 


\section{Data analysis}

The Kappa index was used to describe the agreement between the monofilament test and IpTT. To measure the accuracy of the tests, the researchers analysed sensitivity and specificity, likelihood ratios and predictive values; the Chi squared test was used to compare the tests with the neuropathic symptoms. The level of significance used throughout the study was $5 \%$.

\section{Results}

In the sample study, most individuals were female, obese, not using insulin and not meeting the goals for glycaemic control, as indicated by an HbA1c value higher than 7 . The mean age was 59.43 years, and the mean time since diagnosis was 12.38 years-standard deviation (SD) 10.52, as shown in Tables 1 and 2 .

Using the monofilament test as the gold standard, it was possible to calculate various indicators for the IpTT (sensitivity, specificity, and predictive values).

Out of a total of 250 individuals with diabetes, 36 individuals had a loss of plantar protective sensitivity estimated by the gold standard test (monofilament), which is a prevalence of $14.40 \%$ for the loss of sensitivity. The IpTT presented good results, with a sensitivity of $83.33 \%$ and specificity of $97.66 \%$. Thus, if the patient had loss

Table 1 Descriptive analysis of the qualitative variables of individuals with diabetes $(n=250)$

\begin{tabular}{lll}
\hline Variable & N & Percentage \\
\hline Sex & 72 & 28.8 \\
Male & 178 & 71.2 \\
Female & & \\
Insulin & 118 & 47.2 \\
Yes & 132 & 52.8 \\
No & & \\
HbA1c & 102 & 40.8 \\
Normal<7 & 136 & 54.4 \\
Decompensated $>7$ & 12 & 4.8 \\
Absent & & \\
BMl & 34 & 13.6 \\
Normal & 61 & 24.4 \\
Pre-obesity & 66 & 26.4 \\
Obesity I & 41 & 16.4 \\
Obesity II & 23 & 9.2 \\
Obesity III & & 10 \\
Absent 25 & & \\
Age range & & 44.8 \\
Below 60 & & 55.2 \\
Above 60 & 112 & \\
\hline
\end{tabular}

HbA1c glycated hemoglobina (\%), BMI body mass index

a Years
Table 2 Descriptive analysis of the quantitative variables of individuals with diabetes type $2(n=250)$

\begin{tabular}{lcccc}
\hline Variable & Mean & $\begin{array}{l}\text { Standard } \\
\text { deviation }\end{array}$ & Minimum & Maximum \\
\hline Age $^{\mathrm{a}}$ & 59.43 & 10.78 & 25.0 & 86.0 \\
Time since diagnosis $^{\mathrm{a}}$ & 12.38 & 8.88 & 0.4 & 66.0 \\
Glycated hemoglobin $^{\mathrm{b}}$ & 7.83 & 1.65 & 5.0 & 15.0 \\
BMl & 32.10 & 8.10 & 19.1 & 64.7 \\
\hline
\end{tabular}

$B M I$ body mass index

a Years

b \% percentage

of plantar protective sensitivity, the IpTT presents an 83.33\% probability of identifying the loss of sensitivity (i.e., that the result is truly positive-TP), and if the patient does not have this loss, the IpTT has a $97.66 \%$ probability of identifying this absence (i.e., that the result is truly negative-TN). The positive and negative predictive values were $85.71 \%$ and $97.21 \%$, respectively. Therefore, among the individuals with positive results in the IpTT, the chance of the individual genuinely presenting loss of plantar protective sensitivity is $85.71 \%$, and among the individuals with negative results, the chance of the individual genuinely presenting a loss is $97.21 \%$.

The IpTT was highly accurate when compared with the monofilament test (positive likelihood ratio $=35.61$ ), indicating that the chance of a patient having a loss of sensitivity if the result of the IpTT was positive is 35.61 times greater than a patient with a negative result for the IpTT (Table 4). Table 3 presents a $4 \times 4$ table with the absolute values for patients with and without LOPS.

It may be observed that with the prevalence estimated for this study (14.40\%), the positive predictive value (PPV) is $85.71 \%$, and the negative predictive value (NPV) is $97.21 \%$, as also shown in Table 4 .

The researchers used the Kappa index to assess the agreement between the two tests, with a result of 0.819 $(p<0.001)$, indicating a high level of agreement between both tests, which was statistically significant at the level of significance of $5 \%$ (Table 4 ).

Table 3 Percentage of patients with loss of protective sensation

LOPS with IpTT

\begin{tabular}{lrrr}
\hline & No & Yes & Total \\
\hline LOPS with monofilament & & & \\
No & 209 & 5 & 214 \\
Yes & 6 & 30 & 36 \\
Total & 215 & 35 & 250 \\
\hline
\end{tabular}




Table 4 Sensitivity, specificity and predictive
values of the IpTT for loss of protective sensation,
using the monofilament test as the gold standard,
among individuals with diabetes $(n=250)$

\begin{tabular}{lc}
\hline & IpTT \\
\hline Sensitivity (\%) & 83.33 \\
Specificity (\%) & 97.66 \\
Positive predictive value (\%) & 85.71 \\
Negative predictive value (\%) & 97.21 \\
Positive likelihood ratio & 30.19 \\
Negative likelihood ratio & 0.17 \\
\hline
\end{tabular}

Using Pearson's Chi squared test, the researchers classified the symptoms as mild, moderate or severe and related them to loss of protective sensation in each test. As a result, the researchers identified a relationship of significance between loss of plantar protective sensitivity and severe symptoms $(\mathrm{p}<0.001)$.

\section{Discussion}

Previous studies $[12,18]$ were extremely relevant as support for this work. Their methodology was rigorous, and they were carried out in different environments with different professionals, presenting significant results with regards to their sensitivity and specificity in the use of the monofilament, in addition to their reliability, as indicated by the Kappa levels, in both tests. This investigation showed results similar to those of said studies, with a sensitivity of $(83.33 \%)$ and a specificity of $(97.66 \%)$, while the values found by Rayman 2011 were, respectively, $76 \%$ and $90 \%$, and those found by Sharma et al. $81.2 \%$ and $96.4 \%$.

Therefore, applying the IpTT in this diabetic population, whose sociocultural features are different and whose access to health services is restricted, reiterates the applicability of the test in places that are difficult access or lack proper instruments to screen for ulceration risks.

The study demonstrated that the IpTT is reliable in screening for neuropathy at six points, as the Kappa index was $0.819(\mathrm{p}<0.001)$ compared to the $10 \mathrm{~g}$ monofilament test, showing excellent agreement. It is important to emphasize that although the monofilament test is an easy instrument to handle and is of low cost, it presents high sensitivity and specificity $[19,20]$ for diagnosing the presence of peripheral neuropathy. In this study, most of the patients were female, were obese, were not meeting the goals for glycaemic control, were not using insulin, had a mean age of 59.43 years and had a mean time since diagnosis with diabetes of 12 years. The characteristics found in the sample were similar to those of another multicentre study undertaken in Brazil that evaluated the risk factors for ulceration with regard to sex, mean age,
Table 5 Measures of agreement (Kappa index) between the IpTT and monofilament test, and association of these tests with scores for neuropathic symptoms used in assessing loss of plantar sensitivity in diabetic patients- $(n=250)$

\begin{tabular}{lcc}
\hline & Value & $\boldsymbol{p}$ \\
\hline $\begin{array}{l}\text { Measures of agreement } \\
\text { Measures of association (monofilament v. }\end{array}$ & 0.819 & $<0.001$ \\
$\begin{array}{l}\text { neuropathic symptoms) } \\
\text { (Pearson's Chi squared test) (IpTT v. neuropathic } \\
\text { symptoms) }\end{array}$ & 19.887 & $<0.001$ \\
\hline
\end{tabular}

time since diagnosis with diabetes and $\mathrm{Hba} 1 \mathrm{C}$ values [21]. The mean prevalence of peripheral diabetic neuropathy worldwide varies between 16 and $66 \%[15,19]$. The present study found a percentage of $14.40 \%$ (36) of patients with loss of plantar protective sensitivity (LOPS) with the monofilament test. The lower prevalence found in the present study may be related to the sample size or the need for greater accuracy tests for diagnostic confirmation.

The recommendation both in Brazil and internationally is that patients with type II diabetes should be screened for peripheral neuropathy as soon as they are diagnosed with diabetes [11]; nevertheless, in Brazil, this assessment is rarely carried out by health professionals in primary care due to the lack of instruments such as the monofilament. This negligence to screen for peripheral neuropathy can occur not only because of the lack of instruments but also because of the lack of training of health professionals, who do not know the relevance of this screening. The simple screening method (the IpTT), which presents a good level of agreement and specificity, may serve as a tracking strategy to alert health professionals in places where access is difficult. As patients with diabetes frequently present painful sensory neuropathy and clinical symptoms, such as burning, pain, tingling, and paraesthesia, whose nature is progressive $[2,4,5,11,15]$, and assessed the neuropathic symptoms and classified them as mild, moderate or severe and related them to loss of sensitivity. We concluded that in both the monofilament test and the IpTT, patients who presented more severe neuropathic symptoms presented a significantly greater loss of protective sensation than patients with lower scores (Table 5).

A multicentre study showed similar results with $50 \%$ of patients presented moderate or severe pain [21]. Another study reported that symptoms are not a reliable indicator of neuronal harm, as some patients with symptoms of severe pain have little sensory deficit, while others-without painful symptoms-have feet 
that are completely numb [22]. Currently, a confirmed peripheral neuropathy diagnosis is recommended when the patient has alterations in their nerve conduction speed and one or more abnormal symptoms and signals (pain, burning sensation, tingling, others) [23]. However, if the nerve conduction speed of the patient is normal but there are still questions raised by the presence of said signals and symptoms, validated tests with level. A evidences must be used to evaluate small fiber diabetic neuropathy [24].

Considering that peripheral neuropathy can cause ulceration, is a major public health problem due to its negative impact on psychological and physical health, brings greater mortality, and imposes high costs on the state and family $[25,26]$, it is necessary to encourage health professionals to screen for neuropathy as soon as diabetes is diagnosed in every health service that works with diabetic patients.

\section{Limitations}

This study presents limitations related to its a cross-sectional design. Another limitation is that the tests were undertaken in a single diabetes centre located in Brasília; although it is the only secondary centre in this city, these patients come from various regions or cities located around Brasília, thus characterizing different populations. A further limitation is that the records in the electronic medical records were incomplete regarding BMI and values for $\mathrm{HbA} 1 \mathrm{c}$, vitamin B12 screening was not performed. Few studies have been found, which limits the comparison of our findings with other results.

\section{Conclusion}

We concluded that the results of the IpTT for screening for peripheral neuropathy presented excellent agreement according to the Kappa index $-0.819(\mathrm{p}<0.001)$-in relation to the gold standard and that its results are efficient according to the values presented for sensitivity and specificity. As a result, this means of assessment may be recommended in poor areas where the monofilament is not available for screening, as the IpTT is a simple method of identifying the risk of ulceration. We emphasize that, when the result is inconclusive or negative, it is necessary to perform the test with monofilament or to refer to the performance of other tests with greater accuracy.

\footnotetext{
Abbreviations

ADA: American Diabetes Association; BMI: Body mass index; DSP: Distal symmetric polyneuropathy; HbA1c: Glycated haemoglobin; IpTT: Ipswich Touch Test; LOPS: Loss of plantar sensitivity; IWGDF: International Working Group on the Diabetic Foot; PPV: Positive predictive value; PPN: Negative predictive value; SBD: Brazilian Diabetes Society.
}

\section{Acknowledgements}

We would like to acknowledge Dr. Gerry Rayman, author of the IpTT, who authorized us to use the IpTT in this work, and Hermelinda Pedrosa, M.D. for her contributions in the Diabetic Foot in Brazil Project.

\section{Authors' contributions}

The following individuals have made substantial contributions to the conception and design of this study, the acquisition of data, or the analysis and interpretation of data-LMAD, MCM, FAP, GOL, MCM, RNMF, and MRCGN. The following individuals have been involved in drafting the manuscript or revising it critically for important intellectual content-LMAD, MCM, FAP, GOL, MCM, RNMF, and MRCGN. Each author participated sufficiently in the work to take public responsibility for appropriate portions of the manuscript content-LMAD, MCM, FAP, GOL, MCM, RNMF, and MRCGN. The following individuals have agreed to be accountable for all aspects of this work in ensuring that questions related to the accuracy or integrity of any part of this work are appropriately investigated and resolved-LMAD, MCM, FAP, GOL, MCM, RNMF, and MRCGN. All authors read and approved the final manuscript.

\section{Funding}

This study was funded by the Foundation for Teaching and Research in Health Sciences (Fundação de Ensino e Pesquisa em Ciências da Saúde-FEPECS: Grant No 064.000.028/2017)

Availability of data and materials

The datasets are available upon request from the corresponding author.

\section{Ethics approval and consent to participate}

All procedures performed in studies involving human participants were in accordance with the ethical standards of the institutional and/or national research and complies with the Declaration of Helsinki.

\section{Consent for publication}

The authors grant full authority for article publication and copyright transfer to the journal Diabetology and Metabolic Syndrome.

\section{Competing interests}

The author declares that they have no competing interests.

\section{Author details}

${ }^{1}$ Department of Health, Brasília, Federal District, Brazil. ${ }^{2}$ Center of Neuromuscular Diseases, Hospital de Apoio de Brasilia, Brasília, Federal District, Brazil.

${ }^{3}$ Higher School of Health Sciences, Brasilia, Federal District, Brazil. ${ }^{4}$ University of Brasília, Brasília, Federal District, Brazil.

Received: 4 November 2019 Accepted: 18 March 2020

Published online: 31 March 2020

\section{References}

1. Apelqvist J. Diagnostics and treatment of the diabetic foot. Endocrine. 2012:41(3):384-97. https://doi.org/10.1007/s12020-012-9619-x.

2. Sinnreich M, Taylor BV, Dyck PJ. Diabetic neuropathies: classification, clinical features, and pathophysiological basis. Neurologist. 2005;11(2):63-79. https://doi.org/10.1097/01.nrl.0000156314.24508.ed

3. Tesfaye S, Boulton AJ, Dyck PJ, Freeman R, Horowitz M, Kempler P, et al. Diabetic neuropathies: update on definitions, diagnostic criteria, estimation of severity, and treatments. Diabetes Care. 2010;33(10):2285-93. https://doi.org/10.2337/dc10-1303.

4. Bansal V, Kalita J, Misra UK. Diabetic neuropathy. Postgrad Med J. 2006;82(964):95-100. https://doi.org/10.1136/pgmj.2005.036137.

5. Albers JW, Pop-Busui R. Diabetic neuropathy: mechanisms, emerging treatments, and subtypes. Curr Neurol Neurosci Rep. 2014;14(8):473. https ://doi.org/10.1007/s11910-014-0473-5

6. Dyck PJ, Albers JW, Andersen H, Arezzo JC, Biessels GJ, Bril V, et al. Diabetic polyneuropathies: update on research definition, diagnostic criteria and estimation of severity. Diabetes Metab Res Rev. 2011;27(7):620-8. https:// doi.org/10.1002/dmrr.1226. 
7. Smith AG, Singleton JR. Diabetic neuropathy. Continuum (Minneap Minn). 2012;18(1):60-84. https://doi.org/10.1212/01.CON.0000411568 .34085.3e.

8. Pop-Busui R, Boulton AJM, Feldman EL, Bril V, Freeman R, Malik RA, et al. Diabetic neuropathy: a position statement by the American Diabetes Association. Diabetes Care. 2017;40(1):136-54. https://doi.org/10.2337/ dc16-2042.

9. Sadosky A, Schaefer C, Mann R, Bergstrom F, Baik R, Parsons B, et al. Burden of illness associated with painful diabetic peripheral neuropathy among adults seeking treatment in the US: results from a retrospective chart review and cross-sectional survey. Diabetes Metab Syndr Obes. 2013;6:79-92. https://doi.org/10.2147/DMSO.S37415.

10. American Diabetes Association. Microvascular complications and foot care. Diabetes Care. 2016;39(Suppl 1):S72-80. https://doi.org/10.2337/ dc16-S012

11. Oliveira JEP, Vencio S, editors. Diretrizes da Sociedade Brasileira de Diabetes: 2015-2016. São Paulo: AC Farmacêutica 2016. http://www.epi.uff.br/ wp-content/uploads/2013/10/DIRETRIZES-SBD-2015-2016.pdf.

12. Rayman G, Vas PR, Baker N, Taylor CG Jr, Gooday C, Alder Al, et al. The Ipswich Touch Test: a simple and novel method to identify inpatients with diabetes at risk of foot ulceration. Diabetes Care. 2011;34(7):1517-8. https://doi.org/10.2337/dc11-0156.

13. Madanat A, Sheshah E, Badawy EB, Abbas A, Al-Bakheet A. Utilizing the Ipswich Touch Test to simplify screening methods for identifying the risk of foot ulceration among diabetics: the Saudi experience. Prim Care Diabetes. 2015;9(4):304-6. https://doi.org/10.1016/j.pcd.2014.10.007.

14. Won JC, Park TS. Recent advances in diagnostic strategies for diabetic peripheral neuropathy. Kor Endoc Soc Endocrinol Metab. 2016;31:230-8. https://doi.org/10.3803/EnM.2016.31.2.230.

15. International Diabetes Federation. Diabetic foot screening pocket chart. Brussels: IDF 2017. https://www.idf.org/our-activities/advocacy-aware ness/resources-and-tools/124:diabetic-foot-screening-pocket-chart.html.

16. Grupo de Trabajo Internacional sobre el Pie Diabético. Guía práctica y específica para el tratamiento y la prevención del pie diabético. Brussels: IDF; 2015. http://iwgdf.org/map-es/.

17. Calsolari MR, Nogueira-Machado JA, Vilar L, Pedrosa HC. Mecanismos fisiopatológicos envolvidos na neuropatia diabética. In: Pedrosa HC, Vilar L, Boulton AJ, editors. Neuropatias e pé diabético. São Paulo: AC Farmacêutica; 2013. p. 17-29.

18. Sharma S, Kerry C, Atkins H, Rayman G. The Ipswich Touch Test: a simple and novel method to screen patients with diabetes at home for increased risk of foot ulceration. Diabet Med. 2014;31:1100-3. https://doi. org/10.1111/dme.12450.

19. Pham H, Armstrong DG, Harvey C, Harkless LB, Giurini JM, Veves A. Screening techniques to identify people at high risk for diabetic foot ulceration: a prospective multicenter trial. Diabetes Care. 2000;23(5):60611. https://doi.org/10.2337/diacare.23.5.606.

20. Boulton AJ, Armstrong DG, Albert SF, Frykberg RG, Hellman R, Kirkman MS, et al. Comprehensive foot examination and risk assessment: a report of the task force of the Foot Care Interest Group of the American Diabetes Association, with endorsement by the American Association of Clinical Endocrinologists. Diabetes Care. 2008;31(8):1679-85. https://doi. org/10.2337/dc08-9021.

21. Parisi MCR, Moura Neto A, Menezes FH, Gomes MB, Teixeira RM, Oliveira JEP, et al. Baseline characteristics and risk factors for ulcer, amputation and severe neuropathy in diabetic foot at risk: the BRAZUPA study. Diabetol Metab Syndr. 2016;8:25. https://doi.org/10.1186/s13098-016-0126-8.

22. Tesfaye S, Selvarajah D. Advances in the epidemiology, pathogenesis and management of diabetic peripheral neuropathy. Diabetes Metab Res Rev. 2012;28(Suppl 1):8-14. https://doi.org/10.1002/dmrr.2239.

23. Boulton AJM, Vinik Al, Arezzo JC, Bril V, Feldman EL, Freman R, American Diabetes Association, et al. Diabetic neuropathies: a position statement by the American Diabetes Association. Diabetes Care. 2005;28:956-62. https://doi.org/10.2337/diacare.28.4.956.

24. Malik RA, Veves A, Tesfaye S, Smith G, Cameron N, Zochodne D, Lauria D. Small fibre neuropathy: role in the diagnosis of diabetic sensorimotor polyneuropathy. Diabetes Metab Res Rev. 2011;27:678-84. https://doi. org/10.1002/dmrr.1222

25. Coffey L, Mahon C, Gallagher P. Perceptions and experiences of diabetic foot ulceration and foot care in people with diabetes: a qualitative metasynthesis. Int Wound J. 2016;16(1):183-210. https://doi.org/10.1111/ iwj.13010.

26. Apelqvist J, Bakker K, Van Houtum WH, Nabuurs-Franssen MH, Schaper NC. International consensus and practical guidelines on the management and the prevention of the diabetic foot: international Working Group on the Diabetic Foot. Diabetes Metab Res Rev. 2000;16(Suppl 1):S84-92.

\section{Publisher's Note}

Springer Nature remains neutral with regard to jurisdictional claims in published maps and institutional affiliations.
Ready to submit your research? Choose BMC and benefit from:

- fast, convenient online submission

- thorough peer review by experienced researchers in your field

- rapid publication on acceptance

- support for research data, including large and complex data types

- gold Open Access which fosters wider collaboration and increased citations

- maximum visibility for your research: over $100 \mathrm{M}$ website views per year

At BMC, research is always in progress.

Learn more biomedcentral.com/submissions 